\title{
Review
}

\section{Neuroprotective Effects of the Green Tea Components Theanine and Catechins}

\author{
Takami KAKUDA \\ Central Research Institute, Itoen, Ltd.; 21 Mekami, Sagara-cho, Haibara-gun, Shizuoka 421-0516, Japan. \\ Received April 30, 2002
}

\begin{abstract}
The neuroprotective effects of theanine and catechins contained in green tea are discussed. Although the death of cultured rat cortical neurons was induced by the application of glutamic acid, this neuronal death was suppressed with exposure to theanine. The death of hippocampal CA1 pyramidal neurons caused by transient forebrain ischemia in the gerbil was inhibited with the ventricular preadministration of theanine. The neuronal death of the hippocampal CA3 region by kainate was also prevented by the administration of theanine. Theanine has a higher binding capacity for the AMPA/kainate receptors than for NMDA receptors, although the binding capacity in all cases is markedly less than that of glutamic acid. The results of the present study suggest that the mechanism of the neuroprotective effect of theanine is related not only to the glutamate receptor but also to other mechanisms such as the glutamate transporter, although further studies are needed. One of the onset mechanisms for arteriosclerosis, a major factor in ischemic cerebrovascular disease, is probably the oxidative alteration of low-density lipoprotein (LDL) by active oxygen species. The oxidative alterations of LDL were shown to be prevented by tea catechins. Scavenging of ${ }^{\prime} \mathrm{O}_{2}^{-}$was also exhibited by tea catechins. The neuroprotective effects of theanine and catechins contained in green tea are a focus of considerable attention, and further studies are warranted.
\end{abstract}

Key words tea; theanine; catechin; neuroprotection; glutamate receptor

\section{INTRODUCTION}

The average life span of Japanese in 2000 was 84.6 years for women and 77.6 years for men. Although its people live longer than people elsewhere, Japan's aging population faces new difficulties such as the rising number of senile dementia patients, who have become one of the country's most serious problems. According to Ministry of Health, Labor, and Welfare statistics for 1997, cerebral stroke was the third highest cause of mortality after cancer and heart disease, accounting for $15.7 \%$ of all deaths, or about 138000 people. Of those strokes, $63 \%$ were caused by cerebral infarction, $23 \%$ by cerebral hemorrhage, and $10 \%$ by subarachnoid hemorrhage. Thus the majority of strokes in Japan are cerebral infarctions. If cerebral infarction is severe, with no post ischemic reperfusion, it may result in neuronal death; in cases of slight ischemia with reperfusion, on the other hand, neuronal damage may be minor. However, some brain regions are reported to be particularly vulnerable to ischemia, ${ }^{1,2)}$ and ischemia of only $5 \mathrm{~min}$ can lead to neuronal death about $2 \mathrm{~d}$ later. ${ }^{3)}$ This is thought to be due to the elevation of the extracellular concentrations of the excitatory neurotransmitter glutamic acid with transient cerebral ischemia, ${ }^{4)}$ which induces neuronal damage by its excitotoxicity. ${ }^{4-6}$ ) The relationship between ischemic neuronal death and cerebral vascular dementia has attracted the attention of researchers, and in cases of transient ischemia minimizing neuronal damage after reperfusion is considered vital.

One epidemiological study showed that the incidence of stroke was significantly lower in people who consume more than five cups of green tea (Camellia sinensis) per day. ${ }^{7}{ }^{7} \mathrm{We}$ paid special attention to the $\gamma$-glutamylethylamide (theanine) contained in green tea, which is a compound similar to the excitatory neurotransmitter glutamic acid (Fig. 1), and we investigated the neuroprotective effect of theanine against transient forebrain ischemic neuronal death. Our investigations have demonstrated that theanine has a neuroprotective effect in transient ischemic neuronal death. ${ }^{8)}$ The inhibitory effects of green tea extract and flavonoids on low-density lipoprotein (LDL) oxidation, ${ }^{9,10)}$ and the suppressive effects of tea catechins on lipid peroxidation and inhibition of the incidence of stroke in SHRSP rats ${ }^{11)}$ have also been reported. Based on these findings, the neuroprotective effects of theanine and catechins contained in tea were investigated.

\section{CLASSIFICATION AND CHEMICAL COMPONENTS OF TEA}

The widely accepted scientific name of tea is Camellia sinensis (L.) O. Kuntze. The many varieties of tea include the small-leaf Chinese variety Camellia sinensis var. sinensis, and the large-leaf black tea discovered in India named Camellia sinensis var. assamica. The tea trees cultivated in Japan are thought to have been imported from China by a Zen monk or Japanese envoy to China in the 8th century during China's Tang Dynasty, and are thus of the small-leaf variety $C$. sinensis var. sinensis.

Tea is broadly classified according to the production method as unfermented tea (green tea), half-fermented tea (oolong tea), and full-fermented tea (black tea). The green tea produced in Japan is unfermented tea. The most common production method is steaming, although a small amount of tea in certain districts is produced by panning. This steaming or panning deactivates the oxidase in tea leaves, so that the

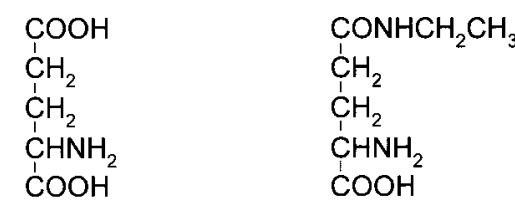

L-glutamic acid Theanine

Fig. 1. Chemical Structure of L-Glutamic Acid and Theanine 
tea retains its brilliant green color, from which it gets the name of green tea. The major chemical components of green tea are shown in Table $1 .^{12)}$ A characteristic of green tea is that it maintains a monomer in the chemical structure of catechins, since it is unfermented, compared with oolong tea or black tea. Theanine and catechins are thought to be the chemical components that confer its neuroprotective effect.

\section{NEURONAL DEATH BY GLUTAMATE TOXICITY}

Glutamic acid plays an important role in memory and learning by producing synaptic plasticity, known as longterm potentiation (LTP) or long-term depression (LTD). Neurons contain between 1 and $10 \mathrm{~mm}$ glutamic acid, which is released from the cell by transmission of an impulse. This glutamic acid contributes to signal transduction by stimulating glutamate receptors and opening ion channels (Fig. 2). Afterward, the glutamic acid is taken into neurons or glial cells by glutamate transporters ${ }^{13)}$ so that the concentration in the extracellular space is maintained at between 1 and $2 \mu \mathrm{M}^{4)} \mathrm{Glu}-$ tamic acid taken into glial cells is transformed to glutamine by the action of glutamine transporters and transferred into neurons, where this glutamine is transformed again to glutamic acid. However, when the intracellular energy source ATP is depleted by injury such as ischemia, depolarization of the neuronal membrane leads to excessive release of glutamic acid and lack of ability to reabsorb this glutamic acid by the glutamate transporter, resulting in an excessive con-

Table 1. Contents of Major Chemical Component (\%) Dry Weights in Green Tea (Goto T., et al. $)^{12)}$

\begin{tabular}{clrccc}
\hline \hline \multirow{2}{*}{ Type of tea } & Grade & Total catechins & Caffeine & Vitamin C & Theanine \\
\hline \multirow{2}{*}{ Gyokuro } & High & 12.02 & 4.03 & 0.17 & 2.35 \\
& Low & 13.69 & 3.53 & 0.21 & 1.52 \\
\multirow{2}{*}{ Matcha } & High & 9.37 & 3.87 & 0.09 & 2.43 \\
& Low & 12.63 & 3.53 & 0.15 & 1.37 \\
\multirow{2}{*}{ Sencha } & High & 15.06 & 3.20 & 0.41 & 1.55 \\
& Low & 16.21 & 2.98 & 0.25 & 0.60 \\
Bancha & - & 13.45 & 2.05 & 0.23 & 0.46 \\
\hline
\end{tabular}

centration of glutamic acid in the extracellular space. This excessive glutamic acid binds to $N$-methyl-D-aspartate (NMDA) and non-NMDA receptors in the postsynaptic membrane, increasing cell permeability to $\mathrm{Ca}^{2+} \cdot{ }^{14-16)} \mathrm{A}$ high concentration of free $\mathrm{Ca}^{2+}$ is thought to cause neuronal death by abnormal activation of various enzymes in the cell. ${ }^{17,18)}$ or by increasing the amount of superoxide radicals. ${ }^{19,20)}$ A correlation has been shown between intracellular concentration of $\mathrm{Ca}^{2+}$ and neuronal death. ${ }^{21)}$ This theoretical relation between glutamic acid/calcium ions and cell death is now widely accepted. ${ }^{22)}$

\section{THEANINE AS A GLUTAMATE ANALOGUE}

Theanine was discovered as a flavorous component of green tea $(C \text {. sinensis })^{23)}$ and is a characteristic component of tea. Theanine was reported to be biologically active in reducing systemic blood pressure, ${ }^{24)}$ producing a relaxation effect, ${ }^{25}$ and suppressing the stimulatory action of caffeine. ${ }^{26,27)}$ Since theanine is an ethylamide and glutamate analogue of the excitatory neurotransmitter glutamic acid (Fig. 1), we paid special attention to the actions of theanine which may compete with glutamic acid to bind the glutamate receptors, thereby suppressing glutamate toxicity and conferring a neuroprotective effect. We then investigated the neuroprotective effect of theanine in both in vitro and in vivo studies, as well as the mechanisms of the posited neuroprotective effects.

4.1. Inhibitory Effects of Glutamate Toxicity by Theanine in in Vitro Studies Nozawa et al. ${ }^{28)}$ exposed cultured rat cortical neurons to between 25 and $800 \mu \mathrm{M}$ of glutamic acid and found that $50 \%$ of the cells died with exposure to glutamic acid $50 \mu \mathrm{M}$. However, the death of cultured rat cortical neurons induced by glutamic acid was suppressed by simultaneous exposure to theanine $500 \mu \mathrm{M}$, ${ }^{29)}$ suggesting the neuroprotective effect of theanine on glutamate toxicity.

4.2. Neuroprotective Effect of Theanine in in Vivo Studies We examined the neuroprotective effect of theanine on postischemic neuronal death in field CA1 of the gerbil hippocampus using a transient ischemia model (Fig. 3). ${ }^{8)}$

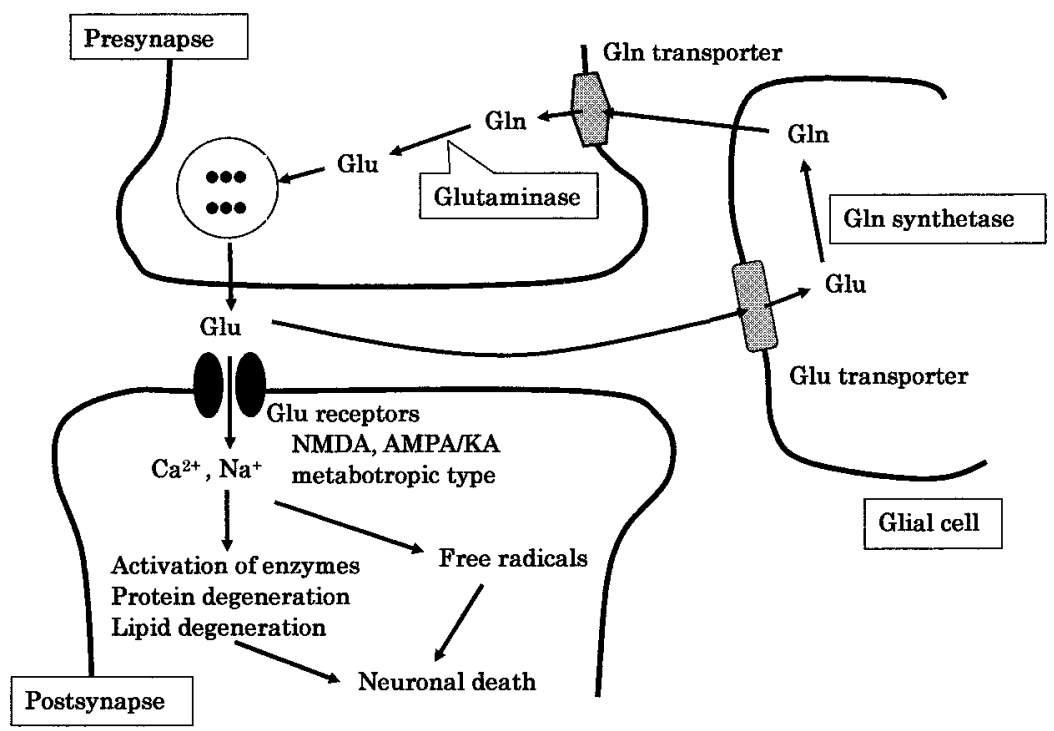

Fig. 2. A Schematic Depiction of the Glutamate Receptor, Glutamine/Glutamate Cycle, and Neuronal Death 

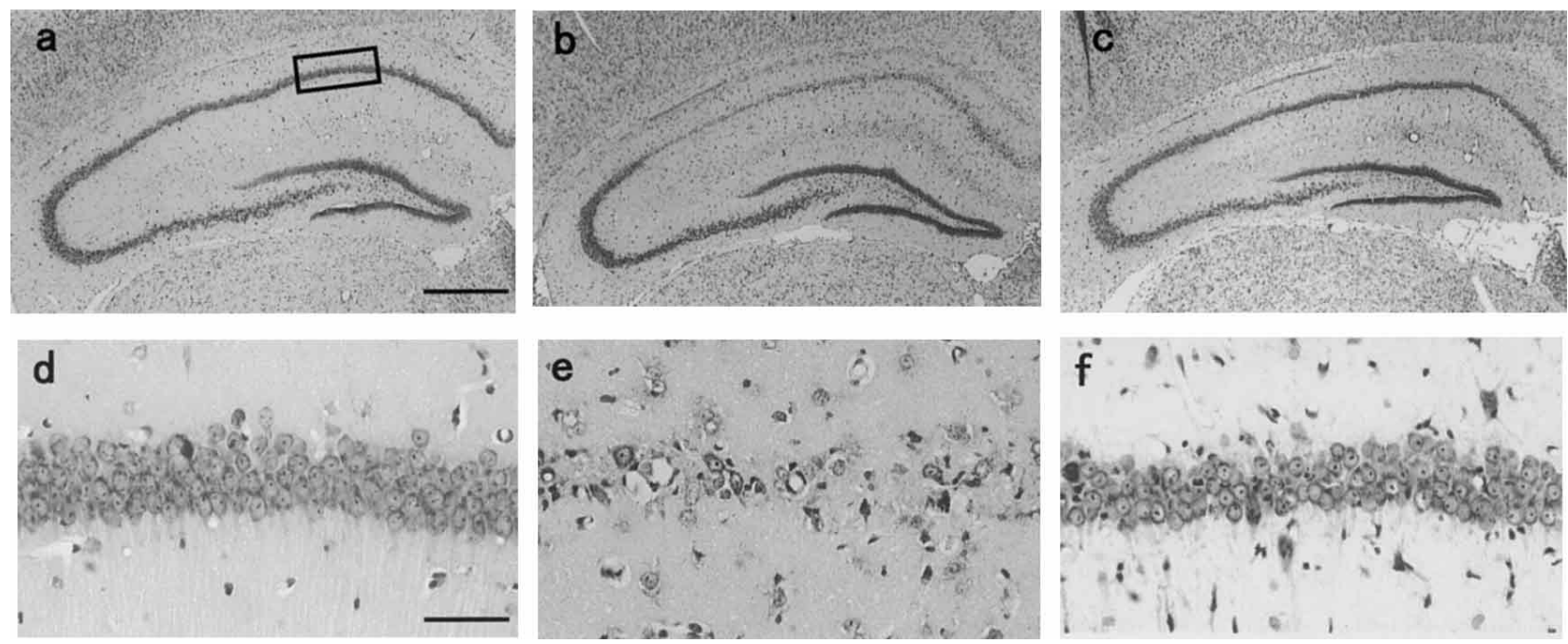

Fig. 3. Photomicrographs of Sections of Hippocampus after Survival for $7 \mathrm{~d}$ Following Administration of Theanine in Animals 30 min before Sham Operation ( $\mathrm{a}, \mathrm{d}$ ), in the Control Group Administered Saline 30 min before 3-min Forebrain Ischemia (b, e), and in the Theanine-Treated Group Administered $1 \mu 1$ of Theanine $500 \mu \mathrm{m} 30 \mathrm{~min}$ before Ischemia (c, f)

Lower photomicrographs show a higher magnification of the CA1 sector. Bars: $500 \mu \mathrm{m}$ in (a), $50 \mu \mathrm{m}$ in (d). Neuronal damage was not observed in the sham-operated group (a, d). Widespread neuronal destruction was observed in the CA1 sector, whereas almost all neurons in the CA3 sector and dentate gyrus were preserved (b, e). Ischemic neuronal destruction in CA1 sector is prevented by theanine administration (c, f). (Kakuda T., et al. $)^{8}$

Transient forebrain ischemia was induced by bilateral occlusion of the common carotid arteries for $3 \mathrm{~min}$, with brain temperature carefully controlled at about $37^{\circ} \mathrm{C}$. The studies were done with the following three experimental groups: 1) sham-operated animals administered theanine $500 \mu \mathrm{M} 30 \mathrm{~min}$ before the sham operation (sham-operated group): 2) control animals administered saline $30 \mathrm{~min}$ before ischemia (control group): and 3) theanine-treated animals administered theanine concentrations of $50 \mu \mathrm{M}, 125 \mu \mathrm{M}$ and $500 \mu \mathrm{M} 30 \mathrm{~min}$ before ischemia (theanine-pretreated group). The theanine solutions were administered with a glass micropipette through a lateral ventricle. Transient forebrain ischemia was induced as described above. Then, after a survival period of $7 \mathrm{~d}$, the animals were deeply anesthetized with pentobarbital and perfused transcardially with heparinized saline followed by $10 \%$ formaldehyde in $0.1 \mathrm{~m}$ phosphate buffer. Their brains were removed and embedded in paraffin. Three coronal sections with a thickness of $4 \mu \mathrm{m}$, taken from a level of $2.0 \mathrm{~mm}$ posterior to the bregma, were made using a microtome and stained with cresyl-violet. The number of intact CA1 neurons in the hippocampus in an ocular grid (rectangle, $500 \mu \mathrm{m}$ wide and $100 \mu \mathrm{m}$ high) was assessed.

In the sham-operated group, the number of CA1 pyramidal neurons was $117 \pm 6$, the same as in a previous study, ${ }^{30)}$ and no neuronal damage was observed. Most CA1 neurons degenerated or disappeared in the control group. In contrast, most CA1 neurons were preserved in the theanine $500 \mu \mathrm{M}$ pretreated group. Ischemic neuronal death in field CA1 of the hippocampus was suppressed in the theanine-pretreated groups in a dose-dependent manner, with approximately $60 \%$ and $90 \%$ survival with theanine $125 \mu \mathrm{M}$ and $500 \mu \mathrm{M}$, respectively. Thus a neuroprotective effect of theanine was also shown against neuronal death in the CA1 region by transient brain ischemia in an in vivo study.

4.3. Mechanism of Theanine Neuroprotection Since theanine is a natural glutamate analogue (Fig. 2), we paid special attention to the action of theanine on glutamate re- ceptors as one of the mechanisms of neuroprotection. To evaluate the binding activity of theanine on glutamate receptor subtypes $(R S)$ - $\alpha$-amino-3-hydroxy-5-methylisoxazole-4propionic acid (AMPA), kainite, and NMDA, we studied the inhibiting effects of theanine on the binding of radiolabeled ligands $\left[{ }^{3} \mathrm{H}\right] \mathrm{AMPA},\left[{ }^{3} \mathrm{H}\right] \mathrm{kainite}$, and the NMDA glycine antagonist $\left[{ }^{3} \mathrm{H}\right]$ MDL195519 to glutamate receptors. ${ }^{31)}$ Since the inhibitory activity of theanine against the binding of radiolabeled ligands to glutamate receptors was shown, it was suggested that theanine acts on glutamate receptors as an antagonist. However, the $\mathrm{IC}_{50}$ value of theanine was about 80 - to 30000 -fold less than that of glutamic acid, and therefore the binding activity of theanine was shown to be very mild. The inhibitory effect of theanine on glutamate receptor subtypes AMPA and kainite receptor was shown to be one order higher than that of the NMDA receptor.

Although the $\mathrm{IC}_{50}$ value of theanine on AMPA receptor was 80-fold lower than that of glutamic acid, the binding concentration was $10^{-5} \mathrm{M}$, which is thought to be pharmacologically effective. ${ }^{31)}$ Sheardown et al. $^{32)}$ reported that the death of CA1 pyramidal neurons was reduced with the administration of AMPA receptor antagonist 2,3-dihydroxy-6nitro-7-sulfamoyl-benzo(F)quinoxaline (NBQX) before and after ischemia, and suggested that AMPA receptors play a functional role in neuronal death induced through NMDA receptors. AMPA receptors generally have a high permeability for $\mathrm{Na}^{+}$, but not for $\mathrm{Ca}^{2+}$. However, it has been suggested that the influx of $\mathrm{Ca}^{2+}$ into the cells is increased by modification of the subunit composition to give $\mathrm{Ca}^{2+}$ permeability and suppression of GluR2 gene expression in the hippocampal CA1 region, which sustains delayed neuronal death following transient ischemia. ${ }^{15,16)}$ This would suggest that theanine contributes to neuroprotection in delayed neuronal death by also acting on AMPA receptors. Nellgård et al. ${ }^{33)}$ reported that neuronal death was prevented by administration of AMPA receptor antagonist even after ischemia, and thus theanine might also prevent neuronal death when adminis- 
tered after ischemia, but further studies on this are needed.

The $\mathrm{IC}_{50}$ value of theanine on kainate receptors was also about 80 -fold lower than that of glutamic acid. While the activity was very low, the binding concentration was $10^{-5} \mathrm{M}$, which is thought to be pharmacologically effective. ${ }^{31)}$ Hippocampal CA3 pyramidal neurons showed the highest uptake of radiolabelled kainate in the brain, ${ }^{34)}$ and were killed with exposure to kainate. ${ }^{35)}$ In our previous study, neuronal death in the hippocampal CA3 region was seen with intraperitoneal injection of kainate $8 \mathrm{mg} / \mathrm{kg}$, but this neuronal death was prevented by the administration of theanine into the ventricle before the intraperitoneal injection of kainate. ${ }^{36)}$ These findings suggest that theanine also binds to kainite receptors as an antagonist, and that theanine plays a role in neuroprotection.

The hippocampal CA1 region, the neurons of which are vulnerable to ischemia, contains many NMDA receptors. ${ }^{34,37)}$ The $\mathrm{IC}_{50}$ value of theanine on NMDA receptors was about 30000-fold less than that of glutamic acid, and one order less than that of AMPA or kainate receptors. Thus, the binding capacity of theanine to NMDA receptors was very low, and the binding concentration was $10^{-4} \mathrm{M}^{31)}$ Maruyama and Takeda. ${ }^{38)}$ suggested that even though the binding capacity of theanine to glutamate receptors is low, theanine may act as a competitive antagonist to glutamate receptors. Yokogoshi et $a l .{ }^{39)}$ reported that the administration of theanine into brain striata increased dopamine release markedly, but that this release was inhibited by pretreatment with D-2-amino-5-phosphonopentanoate (D-APV). These findings suggest that the binding activity of theanine on NMDA receptors is very mild, but that theanine acts on glutamate receptors as an antagonist.

It is known that neuroprotective agents such as MK801 act by lowering the brain temperature. ${ }^{40,41)}$ However, the results of one of our previous studies in which the brain temperature was maintained at $37.5 \pm 0.2^{\circ} \mathrm{C}$ suggest that this is not the case with the neuroprotective effect of theanine. ${ }^{8)}$

The above results suggest that one of the mechanisms of the neuroprotective effects of theanine against neuronal death from transient ischemia is related to the fact that theanine binds to glutamate receptor subtypes such as AMPA, kainate, and NMDA receptors as an antagonist. However, it has been shown that the binding capacity of theanine to glutamate receptors is much lower than that of glutamic acid, which suggests that the antagonistic effect of theanine would be very mild. ${ }^{31)}$ Therefore other mechanisms for the neuroprotective action of theanine in transient ischemia are thought to exist. The glutamic acid discharged from the presynapse acts on glutamate receptors in the postsynaptic membrane. ${ }^{42}$ The $\mathrm{Ca}^{2+}$ channel then opens, and $\mathrm{Ca}^{2+}$ flows into the cells. The extracellular glutamic acid is then taken back up through glutamate transporters in glial cells and the synaptic membrane. ${ }^{21,43,44)}$ Glutamine is then synthesized by glutamine synthetase from the glutamic acid taken into the glial cells. $^{45,46)}$ Glutamine is taken into the presynapse through glutamine transporters. This glutamine is converted to glutamic acid by glutaminase and stored again in synaptic vesicles through a glutamic acid-glutamine cycle. ${ }^{43)}$ Further studies on the effects of theanine on glutamate and glutamine transporters are needed.

4.4. Theanine Metabolism Kitaoka et al. $^{47)}$ reported that theanine, similar to glutamic acid, was absorbed into the blood from the intestinal tract through cotransport with $\mathrm{Na}^{+}$. Unno et $a{ }^{4}{ }^{48)}$ reported that the serum theanine concentration reached a peak 0.5 to $2 \mathrm{~h}$ after oral administration of theanine $200 \mathrm{mg} / \mathrm{kg}$ in rats, and Yokogoshi et al. ${ }^{49)}$ showed that orally administered theanine entered the brain through the bloodbrain barrier. Thus it is clear that orally administered theanine is absorbed into the blood from the intestinal tract, and then a very small amount of theanine in blood flows into the brain through the blood-brain barrier. Therefore further in vivo studies are needed with oral administration of theanine to determine how it confers a neuroprotective effect.

\section{ANTIARTERIOSCLEROTIC EFFECT OF TEA CATE- CHINS}

Arteriosclerosis (atherosclerosis and arteriolosclerosis) is a main cause of ischemic cerebrovascular disease, and prevention of cerebral arteriosclerosis is important in suppressing neuronal death. The relationship between active oxygen species and one of the mechanisms for the development of arteriosclerosis has become a focus of attention. LDL undergoes oxidative changes due to active oxygen species, and this oxidatively altered LDL is ingested by macrophages to form foam cells. ${ }^{50)}$ Therefore inhibiting the formation of oxidatively altered LDL is important in terms of preventing arteriosclerosis.

Green tea also contains catechins such as (-)-epigallocatechin gallate (EGCg), (-)-epigallocatechin (EGC), (-)-epicatechin gallate (ECg), and (-)-epicatechin (EC) at levels of $10-15 \%$ (Fig. 4). The oxidative alterations of LDL were shown to be prevented by tea catechins, ${ }^{51)}$ and oral administration of EGCg in humans reportedly causes a decrease in peroxidative phospholipids and an increase in free catechins in the serum. ${ }^{52)}$ The increase in stroke rate was reported to be lowered and survival time increased by oral administration of catechins over a long period to SHRSP, the radical scavenger effects $^{11)}$ and the preventive effect of lipid peroxidation. ${ }^{51,52)}$ Daily ingestion of tea as an antioxidant has also been reported to prevent stroke. ${ }^{53)}$ The above findings suggest that ingestion of tea containing antioxidant catechins is effective in the prevention of arteriosclerosis.

5.1. Radical Scavenger Effects of Tea Catechins Active oxygen species generated in the body include the superoxide anion radical $\left(\mathrm{O}_{2}^{-}\right)$, hydroxyl radical $\left({ }^{\circ} \mathrm{OH}\right)$, and hyperperoxy radical $\left({ }^{\circ} \mathrm{OOH}\right)$. Of these active oxygen species, ${ }^{\circ} \mathrm{O}_{2}^{-}$ is not as active alone, but ${ }^{\circ} \mathrm{OH}$ and ${ }^{\circ} \mathrm{OOH}$ are generated by

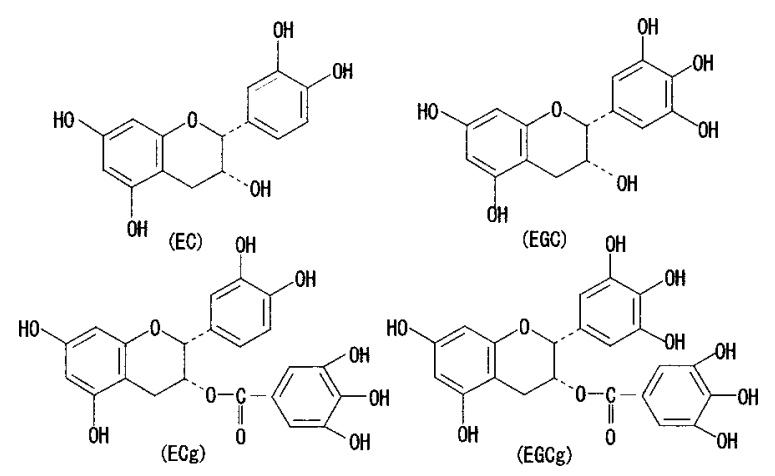

Fig. 4. Chemical Structure of Major Catechins in Green Tea 
$\cdot \mathrm{O}_{2}^{-}$as triggers of the generation of ${ }^{\circ} \mathrm{OH}$ and ${ }^{\circ} \mathrm{OOH}$. Therefore the scavenging of ${ }^{-} \mathrm{O}_{2}^{-}$is important. Unno et al. ${ }^{54)} \mathrm{re}-$ ported a scavenging effect of tea catechins on ${ }^{\circ} \mathrm{O}_{2}^{-}$They used electron-spin resonance to measure the ${ }^{\prime} \mathrm{O}_{2}^{-}$generated from a hypoxanthine (HPX) and xanthine oxidase (XOD) reaction system, and determined the radical scavenging activity of tea catechins to be at the $\mathrm{IC}_{50}(50 \%$ inhibition concentration). Strong scavenging of ${ }^{\circ} \mathrm{O}_{2}^{-}$was exhibited by EGCg (which accounts for about $50 \%$ of tea catechins), EGC, (-)-gallocatechin gallate (GCg), and (-)-gallocatechin (GC). It was suggested that tea catechins, similar to superoxide dismutase (SOD), directly eliminate the $\mathrm{O}_{2}^{-}$that is generated.

5.2. Effect of Tea Catechins on Neuroprotection A small percentage of the catechins consumed in tea are absorbed into the blood vessels from the intestinal tract, ${ }^{55,56)}$ and trace amounts of tea catechins pass through the bloodbrain barrier. ${ }^{56,57)}$ Moreover, it has been reported that neuronal death following transient ischemia was inhibited by oral administration of $(-)$-catechin, ${ }^{58}$ and that green tea polyphenol EGCg has protective effects against hippocampal neuronal damage after transient global ischemia in gerbils. ${ }^{59)}$ These results suggest that the neuroprotective effect of tea catechins is due to prevention of lipid peroxidation and a radical-scavenging effect.

\section{COMPARISON OF THE NEUROPROTECTIVE EF- FECT OF THE GREEN TEA COMPONENTS THEANINE AND CATECHINS WITH PREEXISTING CHEMICALS}

Glutamate receptor antagonists include selective and competitive blockers such as D-APV, and noncompetitive blockers such as MK801, phencyclidine (PCP), and ketamine against NMDA receptors, and NBQX against non-NMDA receptors. $^{32,33)}$ These chemicals exhibited protection against neuronal death with administration before ischemia. ${ }^{32,33,60)}$ However, large amounts of such selective and competitive blockers are needed to bind competitively with large amounts of glutamic acid, and side effects become a problem. ${ }^{60,61)}$ In addition, the side effect of hollowing out the neuron was reported with MK801. ${ }^{60)}$ Moreover, since these chemicals must be administered in a matter of minutes after the onset of ischemic disease, many problems must still be overcome for them to be of practical use. NBQX has been used against AMPA/kainate receptors, and showed effective neuroprotection in preventing delayed neuronal death when administered within $2 \mathrm{~h}$ after the ischemic event. ${ }^{32)}$

On the other hand, since the antagonistic effects of theanine against glutamate receptors were very mild compared with those of glutamic acid, the neuroprotective effects of theanine were less compared with those of clinical agents such as MK801 or NBQX. While tea catechins are very effective in preventing arteriosclerosis through their antioxidant effect and scavenging of active oxygen species, their actions in the brain remain unclear. There is no doubt as to their safety, since most Japanese consume theanine and catechins in green tea almost daily. Therefore it is important to confirm the mechanisms and clinical applications of the neuroprotective effects of the green tea components theanine and catechins to maintain and promote the brain health in an aging society.

\section{CONCLUSIONS}

The neuroprotective effects of theanine in green tea against glutamate toxicity were shown in cultured rat cortical neurons. The death of hippocampal CA1 pyramidal neurons caused by transient forebrain ischemia in the gerbil was inhibited by the ventricular preadministration of theanine. Theanine has a higher binding capacity to the AMPA/kainate receptors than to NMDA receptors, although the binding capacity is markedly less than that of glutamic acid. Thus it is suggested that one of the mechanisms of theanine responsible for its neuroprotective effect is associated with glutamate receptors as an antagonist. However, these findings show that the actions of theanine are very mild compared with those of glutamic acid. Since the results of the present study suggest that the mechanism of the neuroprotective effect of theanine is related not only to the glutamate receptor but also to other mechanisms such as the glutamate transporter, further studies are needed. One of the causes of arteriosclerosis, a major factor in ischemic cerebrovascular disease, is probably the oxidative alteration of LDL by active oxygen species. Since the oxidative alterations of LDL were shown to be prevented and scavenging of ${ }^{\prime} \mathrm{O}_{2}^{-}$was also exhibited by tea catechins, the study of the neuroprotective effects of tea catechins has also attracted attention. Thus the neuroprotective effect of theanine and catechins contained green tea are a focus of considerable attention, and further studies are warranted.

\section{REFERENCES}

1) Diemer N. H., Siemkowicz E., Neuropathol. Appl. Neurobiol., 7, 217-227 (1981).

2) Pulsinelli W. A., Brierley J. B., Plum F., Ann. Neurol., 11, 491—498 (1982)

3) Kirino T., Brain Res., 239, 57-69 (1982).

4) Benveniste H., Drejer J., Schousboe A., Diemer N. H., J. Neurochem., 43, 1369-1374 (1984).

5) Benveniste H., Cerebrovasc. Brain Metab. Rev., 3, 213-245 (1991)

6) Olney J. W., Annu. Rev. Pharmacol. Toxicol., 30, 47-71 (1990).

7) Sato Y., Nakatsuka H., Watanabe T., Hisamichi S., Shimizu H., Fujisaku S., Ichinowatari Y., Ida Y., Suda S., Kato K., Ikeda M., Tohoku J. Exp. Med., 157, 337-343 (1989).

8) Kakuda T., Yanase H., Utsunomiya K., Nozawa A., Unno T., Kataoka K., Neurosci. Lett., 289, 189-192 (2000).

9) Luo M., Kannar K., Wahlqvist M. L., O’Brien R. C., Lancet, 349, $360-361$ (1997).

10) Whalley C. V., Rankin S. M., Hoult J. R. S., Jessup W., Leake D. S., Biochem. Pharmacol., 39, 1743-1750 (1990).

11) Uchida S., Ozaki M., Akashi T., Yamashita K., Niwa M., Taniyama K., Clin. Exp. Pharmacol. Physiol., 1995 (Suppl. 1), S302-303 (1995).

12) Goto T., Yoshida Y., Amano I., Horie H., Foods Food Ingredients J., 170, 46-51 (1996). (In Japanese)

13) Peghini P., Janzen J., Stoffel W., EMBO J., 16, 3822-3832 (1997).

14) Nicholls D., Attwell D., Trends Pharmacol. Sci., 11, $462-468$ (1990).

15) Gorter J. A., Petrozzino J. J., Aronica E. M., Rosenbaum D. M., Opitz T., Bennett M. V., Connor J. A., Zukin R. S., J. Neurosci., 17, 61796188 (1997).

16) Pellegrini-Giampietro D. E., Gorter J. A., Bennett M. V., Zukin R. S., Trends. Neurosci., 10, $464-470$ (1997).

17) Seubert P., Lee K., Lynch G., Brain Res., 492, 366-370 (1989).

18) Arai A., Vanderklish P., Kessler M., Lee K., Lynch G., Brain Res., 555, 276-280 (1991).

19) Lafon-Cazal M., Pietri S., Culcasi M., Bockaert J., Nature (London), 364, 535-537 (1993).

20) Kitagawa K., Matsumoto M., Oda T., Niinobe M., Hata R., Handa N., Fukunaga R., Isaka Y., Kimura K., Maeda H., Mikoshiba K., Kamada T., Neuroscience, 35, 551—558 (1990). 
21) Ogura A., Miyamoto M., Kudo Y., Exp. Brain Res., 73, 447-458 (1988).

22) Choi D. W., Rothman S. M., Ann. Rev. Neurosci., 13, 171-182 (1990).

23) Sakato Y., Nippon Nogeikagaku Kaishi, 23, 262-267 (1949). (In Japanese)

24) Yokogoshi H., Kato Y., Sagesaka M. Y., Takihara-Matsuura T., Kakuda T., Takeuchi N., Biosci. Biotech. Biochem., 59, 615-618 (1995).

25) Kobayashi K., Nagato Y., Aoi N., Juneja L. R., Kim M., Yamamoto T., Sugimoto S., Nihon Nogeikakgaku Kaishi, 72, 153-157 (1998). (In Japanese)

26) Kimura R., Murata T., Chem. Pharm. Bull., 19, 1257-1261 (1971).

27) Kakuda T., Nozawa A., Unno T., Okamura N., Okai O., Biosci. Biotech. Biochem., 64, 287-293 (2000).

28) Nozawa A., Umezawa K., Kobayashi K., Kawahara M., Muramoto K., Kakuda T., Kuroda Y., SFN 28th Annual Meeting, 382.6, 1998. (Abstract)

29) Nozawa A., Umezawa K., Kobayashi K., Muramoto K., Kawahara M., Mizutani A., Kakuda T., Kuroda Y., SFN 25th Annual Meeting, 335.9, 1995. (Abstract)

30) Mitani A., Andou Y., Masuda S., Kataoka K., Neurosci. Lett., 131, $171-174$ (1991).

31) Kakuda T., Nozawa A., Sugimoto A., Niino H., Biosci. Biotech. Biochem., 66, 2002 (in press).

32) Sheardown M. J., Nielsen E. D., Hansen A. J., Jacobsen P., Honoré T., Science, 247, 571-574 (1990).

33) Nellgård B., Wieloch T., J. Cereb. Blood Flow Metabol., 12, 2-11 (1992).

34) Cotman C. W., Monaghan D. T., Ottersen O. P., Storm-Mathisen J., TINS, 10, 273-280 (1987).

35) Ben-Ari Y., Neuroscience, 14, 375-403 (1985).

36) Kakuda T., Nozawa A., Kubo T., Tsukamoto S., SFN 31st Annual Meeting, 335.15, 2001. (Abstract)

37) Monaghan D. T., Holets V. R., Toy D. W., Cotman C. W., Nature (London), 306, 176-179 (1983).

38) Maruyama M., Takeda K., Comp. Biochem. Physiol., 107C, 105-110 (1994).

39) Yokogoshi H., Kobayashi M., Mochizuki M., Terashima T., Neurochem. Res., 23, 667-673 (1998).

40) Busto R., Dietrich W. D., Globus M. Y.-T., Valdés I., Scheinberg P.,
Ginsberg M. D., J. Cereb. Blood Flow Metab., 7, 729-738 (1987).

41) Buchan A., Pulsinelli W. A., J. Neurosci., 10, 311-316 (1990).

42) Fonnum F., J. Neurochem., 42, 1-11 (1984).

43) Amara S. G., Kuhar M., Annu. Rev. Neurosci., 16, 73-93 (1993).

44) Bridges R. J., Kesslak J. P., Nieto-Sampedro M., Broderick J. T., Yu J., Cotman C. W., Brain Res., 415, 163-168 (1987).

45) Norenberg M. D., J. Histochem. Cytochem., 27, 756-762 (1979).

46) Martinez-Hernandez A., Bell K. P., Norenberg M. D., Science, 195, 1356 - 1358 (1977).

47) Kitaoka S., Hayashi H., Yokogoshi H., Suzuki Y., Biosci. Biotech. Biochem., 60, 1768-1771 (1996).

48) Unno T., Suzuki Y., Kakuda T., Hayakawa T., Tsuge H., J. Agric. Food Chem., 47, 1593-1596 (1999).

49) Yokogoshi H., Kobayashi M., Mochizuki M., Terashima T., Neurochem. Res., 23, 667-673 (1998).

50) Steinberg D., Parthasarathy S., Carew T. E., Khoo J. C., Witztum J. L., N. Engl. J. Med., 320, $915-924$ (1989).

51) Miura S., Watanabe J., Tomita T., Sano M., Tomita I., Biol. Pharm. Bull., 12, 1567-1572 (1994).

52) Nakagawa K., Ninomiya M., Okubo T., Aoi N., Juneja L. R., Kim M., Yamanaka K., Miyazawa T., J. Agric. Food. Chem., 47, 3967-3973 (1999).

53) Keli S. O., Hertog M. G., Feskens E. J., Kromhout D., Arch. Intern. Med., 156, 637-642 (1996).

54) Unno T., Sugimoto A., Kakuda T., J. Sci. Food Agric., 86, 601-606 (2000).

55) Unno T., Kazuo K., Itakura H., Takeo T., Biosci. Biotech. Biochem., 60, 2066-2068 (1996)

56) Nakagawa K., Miyazawa T., J. Nutr. Sci. Vitaminol., 43, 679-684 (1997).

57) Suganuma M., Okabe S., Oniyama M., Tada Y., Ito H., Fujiki H., Carcinogenesis, 19, 1771-1776 (1998).

58) Inanami O., Watanabe Y., Syuto B., Nakano M., Tsuji M., Kuwabara M., Free Rad. Res., 29, 359-365 (1998).

59) Lee S., Suh S., Kim S., Neurosci. Lett., 287, 191-194 (2000).

60) Gill R., Foster A. C., Woodruff G. N., J. Neurosci., 7, 3343-3349 (1987).

61) Olney J. W., Labruyere J., Wang G., Wozniak D. F., Price M. T., Sesma M. A., Science, 254, 1515-1518 (1991). 